BULLETIN Bulletin hispanique

HISPANIQUE Université Michel de Montaigne Bordeaux

116-1 | 2014

Varia

\title{
Los gustos del público y la cultura de la guerra en los géneros literarios de ficción del Siglo de Oro español
}

David García Hernán

\section{(2) OpenEdition \\ Journals}

Edición electrónica

URL: http://journals.openedition.org/bulletinhispanique/3007

DOI: 10.4000/bulletinhispanique.3007

ISSN: 1775-3821

Editor

Presses universitaires de Bordeaux

Edición impresa

Fecha de publicación: 1 junio 2014

Paginación: 121-140

ISBN: 978-2-86781-931-5

ISSN: 0007-4640

Referencia electrónica

David García Hernán, « Los gustos del público y la cultura de la guerra en los géneros literarios de ficción del Siglo de Oro español », Bulletin hispanique [En línea], 116-1 | 2014, Publicado el 01 junio 2017, consultado el 23 mayo 2020. URL : http://journals.openedition.org/bulletinhispanique/3007 DOI : https://doi.org/10.4000/bulletinhispanique.3007 


\title{
Los gustos del público y la cultura de la guerra en los géneros literarios de ficción del Siglo de Oro español ${ }^{1}$
}

\author{
David García Hernán \\ Universidad Carlos III de Madrid
}

Il est évident que les écrivains du Siècle d'Or espagnol avaient en tête de satisfaire les goûts du public : les thèmes liés à la guerre étaient particulièrement bienvenus. Une série de messages étaient ainsi délivrés, vraisemblables mais pas toujours conformes à la réalité, qui créaient sur ces questions fondamentales l'état de l'opinion.

Mots-clés: littérature, histoire, guerre, Siècle d'Or espagnol.

Los escritores del Siglo de Oro es obvio que siempre tenían en mente satisfacer los gustos del público, y, para ello, los temas bélicos se mostraban especialmente adecuados. De esta manera se trasmitian una serie de mensajes, verosimiles pero no siempre coincidentes con la realidad, que iban creando unos determinados estados de opinión sobre estas fundamentales cuestiones.

Palabras clave : literatura, historia, guerra, Siglo de Oro.

Obviously, writers in the Spanish "Siglo de Oro" always had in mind to make the public tastes satisfied: for this reason, books about war and warfare were especially convenient. So, by this way, credible - if not always in accordance with reality - messages arrived to the public and made up the public opinion about these main matters.

Keywords: literature, history, war, Spanish Golden Age.

1. Este artículo forma parte del proyecto de investigación «La cultura del linaje y de la estirpe en la literatura del Siglo de Oro. Sus condicionantes y sus implicaciones», financiado por el Ministerio de Economía y Competitividad del gobierno de España, con No de Ref. HAR201235995 y cuyo I.P. es el profesor David García Hernán.

Bulletin Hispanique, Tome 116, n 1 - juin 2014 - p. 121-140. 


\section{El tema bÉLICO y las aficiones Del PÚBlico}

Tal y como se ha puesto de relieve recientemente en diversas publicaciones, no cabe duda de que, ante la auténtica avalancha de títulos sobre estas cuestiones, la guerra y los temas de corte histórico suscitaron enormemente el interés de los escritores en el excelso mundo de la Literatura española del Siglo de $\mathrm{Oro}^{2}$. Tampoco la hay, desde luego, de que buena parte de la proliferación de obras de esta temática se debía en gran medida a los gustos del público. Los consumidores de esta literatura no hacían más que ser el reflejo de una tendencia mayoritaria de la sociedad a la alta consideración de los hechos guerreros, tanto desde un punto de vista político (las conflagraciones bélicas de carácter internacional) como incluso, desde un punto de vista más general, propiamente antropológico (la aceptación generalizada de la idea de la sublimación de la violencia como forma de solucionar conflictos). Pero no sólo los escritores. Como subrayaba con acierto Hale, los maestros de espectáculos y, por supuesto, los artistas, encontraron en la guerra uno de sus temas más recurridos ${ }^{3}$. Como es a todas luces obvio, tarea verdaderamente gigantesca sería la de confeccionar, por ejemplo, un catálogo más o menos exhaustivo sólo de las pinturas relacionadas directa o indirectamente con este tema.

Y es también evidente que los gustos del público, si no de una forma exclusiva, sí al menos influían muy notablemente en los argumentos elegidos por unos autores que perseguían, ante todo, la satisfacción del principal objetivo de un escritor: ser leído. En lo que se refiere al tema bélico, había específicamente una serie de argumentos o motivos que eran de especial predilección por el público, y los tuvieron muy en cuenta los creadores, asimilando así una cultura de la guerra impuesta por los patrones sociales, y contribuyendo con sus obras a que se desarrollara y reprodujera a sí misma. Con ello se ofrecía una visión de los acontecimientos históricos de temática guerrera que no tenía por qué coincidir exactamente con la realidad (estamos hablando de literatura, no de historia) pero que sí al menos debían guardar la verosimilitud debida para mantener la atracción y el interés del lector ${ }^{4}$.

2. Basten tan sólo dos ejemplos. Las obras sobre el tema de Flandes de Lope Vega, Calderón y otros grandes clásicos del Siglo de Oro se pueden contar por decenas; sobre la batalla de Lepanto se puede seguir el rastro de la infinidad de obras literarias publicadas sobre el tema en David García Hernán, "Consecuencias político-culturales de la batalla de Lepanto», Mediterranea. Ricerche Storiche, 23 (2011), pp. 467-500.

3. J. Hale, "War and public opinion in the fifteenth and sixteenth centuries», Past and Present, 22 (1962).

4. Como es sabido, López Pinciano exponía sistemáticamente a finales del siglo XVI la necesidad, para el gusto del público, del rigor de la datación y de la localización espacial y conseguir así la tan importante verosimilitud del contenido argumental de las obras (Alonso López Pinciano, Philosophía Antigua Poética, Madrid, Tomás Junti, 1596. Ed. de Alfredo Carballo Picazo, Madrid, CSIC, 1953, vol. II, pp. 77-78). En los tiempos modernos, el estudio clásico de Riley ya nos advertía, examinando el caso paradigmático de Cervantes, del gran valor que suponían los fundamentos históricos de sus obras para crear un ambiente de verosimilitud de gran atracción para el público (Edward C. Riley, Teoría de la novela en Cervantes, Madrid, 
Esa verosimilitud no sólo permite al historiador actual, con los suficientes contrastes de fuentes y pertrechos metodológicos, llegar a conclusiones de interés sobre este tipo de Historia cultural (lo que había de cierto en las obras de literarias y en qué medida podían afectar en el público), sino que impedía en la mayoría de las ocasiones que una parte mayoritaria del público llegara a discernir claramente entre lo que de verdad era un acontecimiento histórico y lo que había en él de ficción literaria. Y eso, claro está, tenía implicaciones en la generación de estados de opinión social derivados de las representaciones culturales. En una palabra, aunque fuera sin proponérselo directamente, la carga ideológica y propagandística que había, más allá de la tratadística y de la prosa didáctica, en la literatura de ficción de la época centrada en las obras de corte histórico y guerrero, podía ser muy importante. Y, de hecho, lo fue, para deleite del público, satisfacción de los autores, y conveniencia de unas elites gobernantes del país que solían ver en esta literatura un aplauso a sus planteamientos políticos-militares en pos de -en teoría- un objetivo común.

Entre los temas que más se tuvieron en cuenta para fomentar y profundizar en la comunicación autor-público, en los distintos géneros literarios, podemos destacar los que a continuación detallamos en las páginas que siguen.

\section{LA VIDA DEL SOLDADO}

Uno de los temas que despertaba más interés entre el público era el de vida del soldado, muy diferente, desde luego, a la bastante determinista de la mayoría de las profesiones de la época. Abundando en la idea, muchas veces repetida, de Vargas Llosa en el sentido de que el máximo atractivo de la literatura se basa en la posibilidad de vivir, a través de ella, las vidas de los otros, es obvio que los soldados representaban para esto un auténtico filón entre los creadores. De hecho, uno de los principales argumentos que se esgrimían por el capitán y los sargentos reclutadores para cumplir su misión en una bandera de enganche en el ejército era el de «deja que el rey te remunere y verás mundo» . Es decir, la posibilidad de escapar a un futuro my previsible y determinista, que no se presentaba con demasiadas aventuras ni acciones vitales intensas y dinámicas. Una importante parte de esta perspectiva se puede ver, por ejemplo, dentro de la narrativa del Siglo de Oro, y más concretamente en el cuento. En el Patrañuelo de Timoneda, se transmite claramente la idea de que servir al rey es ver mundo. Concretamente, en la patraña diecisiete, hablando de que el rey de Tracia se había perdido en el bosque y que fue a parar a un mesón que regentaba un matrimonio que tenía un hijo de 15 años, se expone:

...Como estuviesen cenando y el rey viese a Julián cuán bien criado y servicial era,

díjole al padre:

-Decidme, señor, ¿por qué tenéis este mozo aquí perdido? Dejadlo que vaya a ver el mundo algún poco de tiempo, que no puede perder nada en ello.

Taurus, 1966). 
-No nos miente tal, por amor de Dios, señor, que ya una vez, semonos quiso ir con una escobeta a la guerra, y de puras lágrimas mías le hize que se quedase 5 .

El personaje del soldado aparece en infinitas obras de teatro del Siglo de Oro. Poco a poco se fue creando una imagen de éste con unas determinadas características que se fue propagando extraordinariamente en todos los ámbitos sociales. Una definición, concisa, pero muy significativa de esas características y, en general del propio soldado, la da con toda claridad el capitán Castillo, personaje protagonista en la comedia lopesca Los guanches de Tenerife, cuando se dirige al ángel que "guía» los pasos de los españoles:

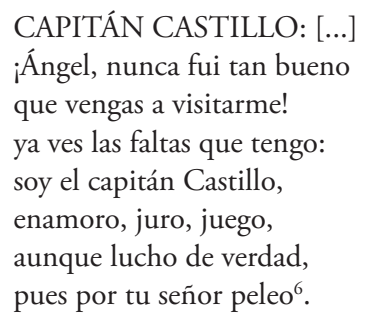

Pero, a pesar de estos últimos elevados intereses (coincidentes con lo expuesto en los mensajes propagandísticos de una monarquía que planteaba las relaciones internacionales como una cuestión divina, y con un alto sentido providencialista) los soldados tenían muy claro que era en la guerra y con la guerra como podían medrar y atender a sus ansias materiales. Y la literatura también ponía de manifiesto los excesos que se podían derivar de las circunstancias de su profesión. El soldado plático Guzmán en la obra de significativo título Soldadesca, de Torres Naharro, lo expresaba también con claridad:

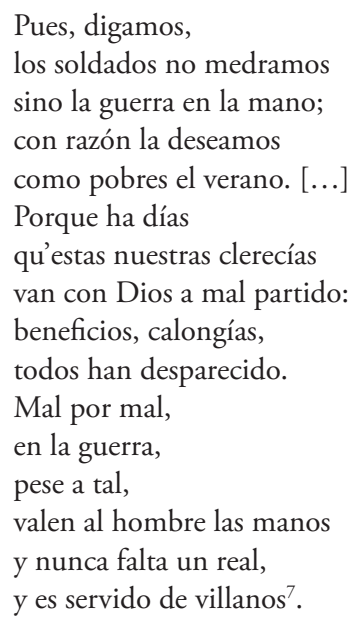

5. Juan de Timoneda, El patrañuelo, en F. Navas López y E. Soriano Palomo (Eds.), Cuentos del siglo de Oro, Madrid, Castalia, 2001, p. 52.

6. Lope de Vega, Los guanches de Tenerife, edición de Madrid, 1961, Acto I, Cuadro III.

7. B. Torres Naharro, Soldadesca, Madrid, edición de D.W. Mc Pheeters, Madrid, 1984. Jornada I, p. 58. 
Luego la imagen del soldado, como la de otros muchos aspectos relacionados con la guerra, no es uniforme ni monolítica, sino, como ocurría en la realidad, llena de aristas y aspectos diversos, entre los que se contaba lo mejor y lo peor del oficio de servir las banderas del rey.

\section{Sublimación de la Violencia}

Como hemos anticipado, la perspectiva más general y antropológica de la estima de los hechos violentos como un valor de consideración, y no como un defecto, está bien presente en la cultura de la guerra que se transmite en las representaciones del Siglo de Oro. Hay un ensalzamiento de lo bélico y, en general, de la violencia en muchas obras muy importantes y representativas de este periodo. En la narrativa, la muy difundida y valorada -entonces y ahoranovela de aventuras basada en la vida del capitán Alonso de Contreras, se ve clarísimamente esta «afición» desde el principio. Desde los años de más tierna infancia del protagonista, se puede ver cómo éste se va abriendo camino en muchos momentos a partir de la violencia, que forma parte importante de su vida ya entonces, incluso mucho antes de ejercer como soldado ${ }^{8}$.

En general, en toda la literatura hispana de esta época, con los colores más vivos y los versos más encendidos, se cantan los sucesos heroicos de la guerra, que transitan todos los géneros historiográficos. En la comedia El asalto de Mastrique, de Lope de Vega, el soldado Alonso relata, con esa crudeza que recuerda la nueva oleada asombrosa y desagradablemente realista de cine bélico, los momentos cruciales del asalto a aquella ciudad, donde, corriendo los siglos, se firmará, muy contradictoriamente con este hecho y con los horrores que se cantan de él en la mencionada obra, un importante tratado en el proceso de unidad europea: Maastricht. Los versos hablan por sí solos:

$$
\begin{aligned}
& \text { asalta el fuerte Mastrique } \\
& \text { y a sus murallas asesta } \\
& \text { cuarenta cańones juntos } \\
& \text { y diez culebrinas fieras; } \\
& \text { brama el sonoro bronce, } \\
& \text { las almas de hierro vuelan, } \\
& \text { vertiendo fuego las bocas } \\
& \text { forma el humo nubes densas; } \\
& \text { huyen las aves del aire, } \\
& \text { los montes lejos resuenan, } \\
& \text { que sin preguntarles nada } \\
& \text { dan a los tiros respuesta; } \\
& \text { ni los que llevan se ven, } \\
& \text { ni lo saben los que quedan, } \\
& \text { que la prisa del batir } \\
& \text { todo lo confunde en niebla; } \\
& \text { manda Alejandro dar voces, }
\end{aligned}
$$

8. A. de Contreras, Discurso de mi vida; cito por la edición de Madrid, 2005. 


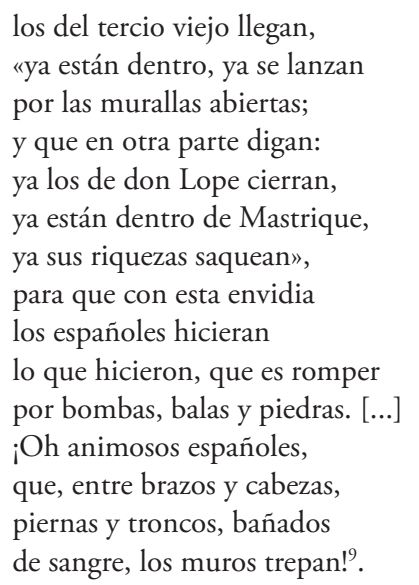

Como podemos ver a través de estos terribles versos, la imagen de los cuerpos despedazados resalta la crueldad y crudeza del encuentro. Una imagen que se encuentra también en otras muchas obras y géneros, como en la poesía épica. En uno de los libros más importantes del periodo, La Araucana, de Alonso de Ercilla, se pueden ver ciertos rasgos de sadismo en la descripción de las feroces luchas en Chile entre españoles y araucanos. Una descripción que se hace en unos términos muy semejantes a los que acabamos de ver. En el Canto III se dice textualmente:

Salen los españoles de tal suerte los dientes y las lanzas apretando, que de cuatro escuadrones, al más fuerte le van un largo trecho retirando: hieren, dañan, tropellan, dan la muerte, piernas, brazos, cabezas cercenando: los bárbaros por esto no se admiran, antes cobran el campo y los retiran ${ }^{10}$.

Más adelante, en este mismo Canto III:

Del rigor de las armas homicidas los templados arneses retenían, y las vivas entrañas escondidas con carniceros golpes descubrían: cabezas de los cuerpos divididas, que aún el vital espíritu tenían, por el sangriento campo iban rodando, vueltos los ojos ya paladeando ${ }^{11}$.

9. Lope de Vega, El asalto de Mastrique, Estudio preliminar de Marcelino Menéndez Pelayo, B.A.E. Madrid, 1969, Acto III.

10. A. de Ercilla y Zúñiga, La Araucana; cito por la edición de Madrid de 1993, Canto III. 11. A. de Ercilla y Zúńiga, La Araucana; cito por la misma edición de Madrid de 1993, Canto III. 
Y en el canto VIII se dice también:

De tullir y mancar no se contenta, ni para contentarse esto le basta; sólo de aquellos tristes hace cuenta que su maza los hace torta o pasta: rompe, magulla, muele y atormenta, desgobierna, destroza, estropia y gasta: tiros llueven sobre él arrojadizos cual tempestad furiosa de granizos.

Pero sin miedo el bárbaro sangriento por las espesas armas discurría; brazos, cabezas y ánimos sin cuento soberbios quebrantó en solo aquel día; y cual menuda lluvia por el viento la sangre y frescos sesos esparcía: no discierne al pariente del extrańo,

Alvarado con ánimo y cordura los anima y esfuerza, y no aprovecha; que la turbada gente en tal rotura huye la muerte y plaza tan estrecha: cuál encamina al monte, y cuál procura de Mapochó la senda más derecha, y cuál y cuál constante todavía, animoso con Átropos porfía.

Estos, honrosa muerte deseando, despreciaban la vida deshonrada, aquel forzoso punto dilatando con raro esfuerzo y valerosa espada: presto quedó la plaza sin un bando, de almas vacía y de cuerpos ocupada, que animosos los pocos que quedaban a las armas y muerte se entregaban.

Unos por los costados caen abiertos; otros de parte a parte atravesados; otros, que de su sangre están cubiertos, se rinden a la muerte desangrados: al fin, todos quedaron allí muertos, del riguroso hierro apedazados. Vamos tras los que aguijan los caballos, que no haremos poco en alcanzallos ${ }^{12}$.

"La sangre y frescos sesos esparcía». Como vemos, los rigores de la guerra se transmiten sin ningún tipo de miramientos, con una carga de brutalidad, e incluso obscenidad, que pueden sorprender al lector de nuestro tiempo si no está avisado de este ensalzamiento de la cultura de la guerra que estamos viendo.

Pero esta crueldad de la lucha en La Araucana no se refleja solo en el 
enfrentamiento entre españoles e indígenas. Cuando se recogen las noticias sobre la batalla de San Quintín (dentro de la inserción que hace Ercilla en su poema de temática americana de los hechos más sobresalientes de su época también en el continente europeo) los versos son igualmente impactantes:

$$
\begin{aligned}
& \text { Vieran en las entradas defendidas } \\
& \text { gran contienda, revuelta y embarazos, } \\
& \text { muertes extrañas, golpes y heridas } \\
& \text { de poderosos y gallardos brazos; } \\
& \text { cabezas hasta el cuello y más hendidas, } \\
& \text { y cuerpos divididos en pedazos: } \\
& \text { que no bastaban petos ni celadas } \\
& \text { contra el crudo rigor de las espadas }{ }^{13} \text {. }
\end{aligned}
$$

De la misma manera, imágenes significativamente muy parecidas nos encontramos en el final de la comedia de Lope de Vega La Santa Liga, sobre la batalla de Lepanto. La victoria de los cristianos se celebra viendo los espectadores la cabeza de Alí Baja ensartada en una pica; además de que en los últimos versos se llame varias veces perro a Solimán:

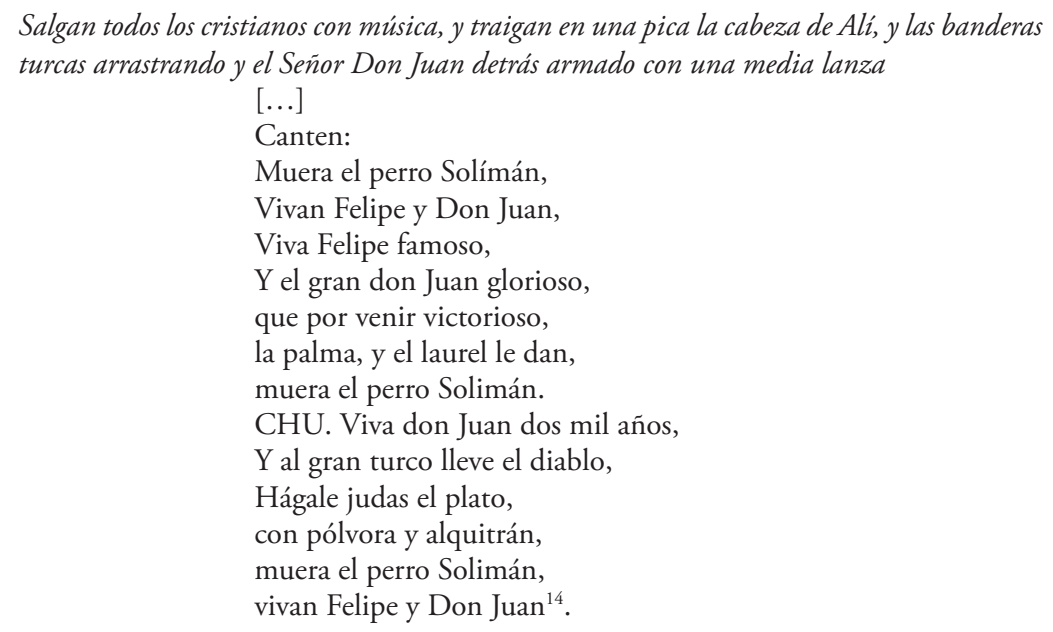

Todas estas coincidencias en cuanto, por ejemplo, a las imágenes de los cuerpos despedazados, no se pueden explicar, obviamente, más que a través de la importancia de los gustos de un público que tenía en estos hechos de extrema violencia uno de sus "pasatiempos» preferidos, en una época donde la asistencia a un auto de fe o a una ejecución pública era todo un espectáculo. Estas representaciones culturales no hacen sino confirmar aquella aseveración de una obra ya clásica del periodo en el sentido de que la época del Renacimiento tenía un sesgo de sadismo ${ }^{15}$.

13. A. de Ercilla y Zúñiga, La Araucana; cito por la edición de Madrid de 1993, Canto XVIII. 14. Lope de Vega, La Santa Liga..., en Decima quinta parte de las comedias de Lope de Vega Carpio, Madrid, 1621, acto III.

15. J.R. Hale, Guerra y sociedad en la Europa del Renacimiento (1450-1620), Madrid, 1990, p. 95. 


\section{Supremacía de lo español}

Por supuesto, uno de los temas que más podía enardecer a un público deseoso de ser complacido era el de presentar la imagen del espańol, o de lo español en general, como superior frente a otras naciones y pueblos de la tierra. Como es natural, esto lo sabían los autores perfectamente, lo aprovechaban hasta niveles máximos, y con diferentes vertientes y matices que presentaban las innumerables ventajas de pertenecer a este pueblo poco menos que elegido por Dios.

En la narrativa, por ejemplo, Lope de Vega en la novela bizantina y de aventuras El peregrino en su patria (publicada, con un gran e inmediato éxito en Sevilla en 1604), se presenta a un alemán que advierte la presencia de un español y su cultura (que le capacitaba para hablar en latín), y, entablando conversación con él, se lamenta de que su patria estuviera infestada de errores del demonio:

Alegrose el alemán de que en el español hubiese capacidad para tratar con él humildes cosas, que es insufrible trabajo caminar al lado del que por lo menos ignora la lengua latina, cuando no sepa otro género de facultad, y así, discurriendo en diversas cosas le preguntó la causa de su viaje a Espańa y si sólo había sido visitar algunos santos lugares que ay en ella. A lo cual replicando el más entendido le dijo así: -Está aquella nuestra mísera y infelicísima tierra tan infestada de errores que el Demonio y sus ministros han sembrado en ella que para salir del peligro que podía correr mi salvación, (como el que huye del lugar inficionado), elegí la Católica España por asilo, donde habiendo estado algunos años (bien lo conocerás en mi lengua), no quise salir della sin visitar las estaciones que tiene tan dignas de maravillosa veneración ${ }^{16}$.

Siguiendo con la narrativa, en otras ocasiones se muestra la superioridad española a través de las discusiones y pendencias entre nacionales y extranjeros, en las que, por supuesto, salen siempre victoriosos los hispanos. En El diablo cojuelo, de Luis Vélez de Guevara, se presenta una pendencia contra extranjeros que llevan a cabo, en una venta, los personajes de don Cleofás y el cojuelo, por defender la superioridad del rey de España, con esta larga pero interesante discusión:

El italiano preguntó a don Cleofás que de adónde venía, y él le respondió que de Madrid. Repitió el Italiano:

-¿Qué nuevas hay de guerra, señor Español?

Don Cleofás le dijo:

-Ahora todo es guerra.

-Y ¿̨contra quién dicen? -replicó el Francés.

-Contra todo el mundo -le respondió don Cleofás-, para ponerlo todo él a los pies del Rey de España.

-Pues a fe -replicó el Francés- que primero que el Rey de España...

$\mathrm{Y}$ antes que acabase la razón el Gabacho, dijo don Cleofás:

-El Rey de Espańa...

Y el Cojuelo le fue a la mano, diciendo:

-Déjame, don Cleofás, responder a mí, que soy español por la vida, y con quien vengo, vengo; que les quiero con alabanzas del Rey de España dar un tapaboca a estos

16. Lope de Vega, El peregrino en su patria (cito por la edición de 1971 de la Universidad de Carolina del Norte cuidada por Myron A. Peyton), p. 225. 
borrachos, que si leen las historias de ella, hallarán que por Rey de Castilla tiene virtud de sacar demonios, que es más generosa cirugía que curar lamparones.

Los extranjeros, habiendo visto callar al español, estaban muy falsos, cuando el Cojuelo, sentándose mejor y tomando la mano, y en traje castellano que ya había dejado a la guardarropa del viento el turquesco, les dijo:

-Señores míos, mi camarada iba a responder, y a mí, por tener más edad, me toca el hacerlo; escúchenme atentamente, por caridad. El Rey de España es un generosísimo lebrel, que pasa acaso solo por una calle, y no hay gozque en ella que a ladrarle no salga, sin hacer caso de ninguno, hasta que se juntan tantos, que se atreve uno, al desembocar de ella a otra, pensando que es sufrimiento y no desprecio, a besarle con la boca la cola; entonces vuelve, y dando una manotada a unos y otra a otros, huyen todos, de manera que no saben dónde meterse, y queda la calle tan barrida de gozques y con tanto silencio, que aun a ladrar no se atreven, sino a morder las piedras, de rabia. Esto mismo le sucede siempre con los reyes contrarios, con las seńorías y potentados, que son todos gozques con Su Majestad Católica; pero guárdese el que se atreviere a besarle la cola; que ha de llevar manotada que escarmiente de suerte a los demás, que no hallen dónde meterse, huyendo de él.

Los extranjeros se comenzaron a escarapelar, y el Francés le dijo:

-iAh, bugre, coquín español!

Y el Italiano:

-¡Forfante, marrano español!

Y el Inglés:

-¡Nitesgut español!

Y el Tudesco estaba de suerte, que lo dio por recibido, dando permisión que hablasen los demás por él en aquellas cortes.

Don Cleofás, que los vio palotear y echar espadañas de vino y herejías contra lo que había dicho su camarada, acostumbrado a sufrir poco y al refrán de «quien da luego, da dos veces», levantando el banco en que estaban sentados los dos, dio tras ellos, adelantándose el compañero con las muletas en la mano, manejándolas tan bien, que dio con el Francés en el tejado de otra venta que estaba tres leguas de allí, y en una necesaria de Ciudad Real con el Italiano, porque muriese hacia donde pecan, y con el Inglés, de cabeza en una caldera de agua hirviendo que tenían para pelar un puerco en casa de un labrador de Adamuz; y al Tudesco, que se había anticipado a caer de bruces a los pies de don Cleofás, le volvió al Puerto de Santa María, de donde había salido quince días antes, a dormir la zorra. El Ventero se quiso poner en medio, y dio con él en Peralvillo, entre aquellas cecinas de Gestas, como en su centro ${ }^{17}$.

En el teatro también podemos ver planteamientos muy semejantes. En $E l$ Sitio de Breda Calderón hace decir a Don Fadrique Bazán algo tan significativo como:

$$
\begin{aligned}
& \text { Ya sabe } \\
& \text { que siempre los españoles } \\
& \text { son en la milica soles }{ }^{18} \text {. }
\end{aligned}
$$

Y más adelante, en la jornada II de esta misma obra, dice el marqués de Espínola:

17. Luis Vélez de Guevara, El diablo cojuelo, (primera edición de 1641), cito por la edición de Enrique Rodríguez Cepeda, Madrid, Cátedra, 1984, pp. 113-116.

18. P. Calderón de la Barca, El sitio de Breda, B.A.E., Vol. 7, T.I, Madrid, 1944, Jornada I, Escena VI, p. 112. 


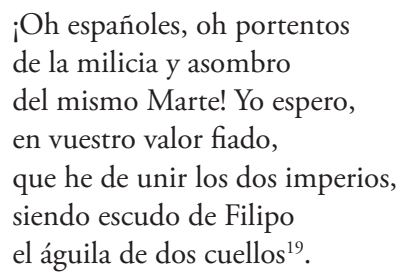

Por otra parte, en el auto sacramental El primer blasón del Austria, también de Calderón, el rey de Hungría se siente seguro porque le acompañan las armas españolas ante la próxima batalla de Nördlingen contra los suecos. Y lo hace de una forma tan directa como la que nos muestra cuando se dirige al CardenalInfante en estos términos:

REY: De todo el mundo me veré temido con tal hermano y tal amigo al lado; desde hoy ya desestimo, ya desprecio las arrogantes armas del soecio $[\text { sueco }]^{20}$.

\section{El SOLDAdo ESPAÑol Y LAS DAMAS}

Otro tema muy recurrente, que daba amplias posibilidades a los autores porque era muy bien recibido entre el público, era el de la pretendida atracción que tenían las mujeres por los españoles, especialmente los soldados, tan solo por el mero hecho de tener ambas condiciones.

En la narrativa esto lo vemos con claridad en múltiples ocasiones, como, por ejemplo, en la novela ejemplar de Cervantes La Española inglesa, cuando el personaje español Ricaredo vuelve victorioso de su batalla naval a Londres con un semblante físico absolutamente admirable. La situación cortesana que se produce no puede ser más favorable hacia la consideración del gran atractivo que despiertan los españoles entre las mujeres:

Estaba con la reina, con las otras damas, Isabela, vestida a la inglesa, y parecía tan bien como a la castellana. Antes que Ricaredo llegase, llegó otro que dio las nuevas a la reina de cómo Ricaredo venía. Alborozose Isabela oyendo el nombre de Ricaredo, y en aquel instante temió y esperó malos y buenos sucesos de su venida.

Era Ricaredo alto de cuerpo, gentilhombre y bien proporcionado. Y, como venía armado de peto, espaldar, gola y brazaletes y escarcelas, con unas armas milanesas de once vistas, grabadas y doradas, parecía en extremo bien a cuantos le miraban; no le cubría la cabeza morrión alguno, sino un sombrero de gran falda, de color leonado con mucha diversidad de plumas terciadas a la valona; la espada, ancha; los tiros, ricos; las calzas, a la esguízara. Con este adorno y con el paso brioso que llevaba, algunos hubo

19. Ibidem., El sitio de Breda, B.A.E., Vol. 7, T. I, Madrid, 1944, Jornada II, Escena VII, p. 117.

20. P. Calderón de la Barca, El primer blasón de Austria, Estudio y edición de Enrique Rull y José Carlos de Torres, Madrid, 1981. 
que le compararon a Marte, dios de la batallas, y otros, llevados de la hermosura de su rostro, dicen que le compararon a Venus, que, para hacer alguna burla a Marte, de aquel modo se había disfrazado ${ }^{21}$.

Ricaredo, en este contexto, se va a encontrar espléndidamente agasajado por unas damas cortesanas que llegan a decir que, viendo tanta hermosura masculina, la guerra tiene que ser muy bella:

Entróse la reina en una sala, y las damas rodearon a Ricaredo; y una dellas, que había tomado grande amistad con Isabela, llamada la señora Tansi, tenida por la más discreta, desenvuelta y graciosa de todas, dijo a Ricaredo:

-¿Qué es esto, señor Ricaredo, qué armas son éstas? ¿Pensábades por ventura que veníades a pelear con vuestros enemigos? Pues en verdad que aquí todas somos vuestras amigas, si no es la señora Isabela, que, como española, está obligada a no teneros buena voluntad.

-Acuérdese ella, señora Tansi, de tenerme alguna, que como yo esté en su memoria -dijo Ricaredo-, yo sé que la voluntad será buena, pues no puede caber en su mucho valor y entendimiento y rara hermosura la fealdad de ser desagradecida. A lo cual respondió Isabela:

-Señor Ricaredo, pues he de ser vuestra, a vos está tomar de mí toda la satisfación que quisiéredes para recompensaros de las alabanzas que me habéis dado y de las mercedes que pensáis hacerme.

Estas y otras honestas razones pasó Ricaredo con Isabela y con las damas, entre las cuales había una doncella de pequeña edad, la cual no hizo sino mirar a Ricaredo mientras allí estuvo. Alzábale las escarcelas, por ver qué traía debajo dellas, tentábale la espada y con simplicidad de niña quería que las armas le sirviesen de espejo, llegándose a mirar de muy cerca en ellas; y, cuando se hubo ido, volviéndose a las damas, dijo:

-Ahora, señoras, yo imagino que debe de ser cosa hermosísima la guerra, pues aun entre mujeres parecen bien los hombres armados.

- ¿Y cómo si parecen? -respondió la señora Tansi-; si no, mirad, a Ricaredo, que no parece sino que el sol se ha bajado a la tierra y en aquel hábito va caminando por la calle $e^{22}$.

Y este «hábito» era, ciertamente, muy importante. Por ello es un tema también bastante recurrido, sobre todo porque los adornos militares daban un extraordinario juego en la literatura para subrayar la apostura y belleza de los tipos españoles. Igualmente se puede ver en el Poema Trágico del español Gerardo, de Gonzalo Céspedes y Meneses, la consideración de que el traje del soldado es un gran adorno para el hombre, llevando incluso el razonamiento un rechazo implícito (como efectivamente se hará en la organización del ejército por lo menos hasta el siglo XVIII) del uniforme, que suponía una cierta despersonalización del carácter singular del soldado. En el discurso segundo de la mencionada obra se dice textualmente:

21. Miguel de Cervantes Saavedra, La Española inglesa, (novela bizantina con primera edición en 1613), (cito por la edición de Madrid, 1991), p. 28. De esta novela se ha estudiado su alto grado de historicidad en función de los objetivos de Cervantes de atraer al público a partir del rigor cronológico-histórico de los hechos, de los personajes y de los lugares. Vid. José Montero Reguera, "La española inglesa y la cuestión de la verosimilitud en la novelística cervantina», en Actas del IV Congreso Internacional de la Asociación Internacional Siglo de Oro, Alcalá de Henares, 1998, Vol. 2, pp. 1071-1078.

22. Miguel de Cervantes Saavedra, Ibid., pp. 29-30. 
Los primeros días, con la licencia que para variedad de colores, bandas y plumas, da el nombre de soldado, anduve acompañado de amigos, dando diversos bordes y rumbos a la ciudad [de Granada]: y no sé si las militares galas, o mi contraria suerte, inclinaron los ojos de una dama y hermosa por extremo, y por extremo noble, a que con más cuidado reparasen en mi persona ${ }^{23}$.

También se ve con toda claridad la faceta del lucimiento del soldado especialmente ante las mujeres en la famosa Vida del escudero Marcos de Obregón, de Vicente Espinel. Entre los largos e intensos avatares de su vida que pone de manifiesto el protagonista se puede leer:

Salí de Santander, y tomé mi derrota por Laredo y Portugalete: llegué a Bilbao, donde me siguió mi fortuna, como suele. Aunque no iba muy recio ni convalecido, llevaba algunas galillas de soldado; y como aquella armada había dado tan grande tronido, todos gustaban de ver soldados de ella. Las mujeres particularmente como más noveleras, salían a ver cualquiera soldado que venía ${ }^{24}$.

Igualmente, se puede ver también la atracción que sienten las mujeres por los hechos de los soldados en la vida del no menos famoso Alonso de Contreras. Después de un acto de bravuconería en la putería de Córdoba (donde el protagonista había herido en una riña a un alguacil), una viuda de la ciudad quiere tener una entrevista con él; y simple y llanamente le dice que está dispuesto a ofrecerle sus encantos por el atractivo que tenían para ella los modos violentos y propios de los soldados (por otra parte, ajenos a toda legalidad) que había tenido Contreras para solventar la situación ${ }^{25}$.

En el teatro, la situación es todavía más efectista. Son también en este sentido muy significativos (que apenas dan lugar a comentario por su expresividad) los versos de la flamenca Aynora en El asalto de Mastrique, de Lope de Vega:

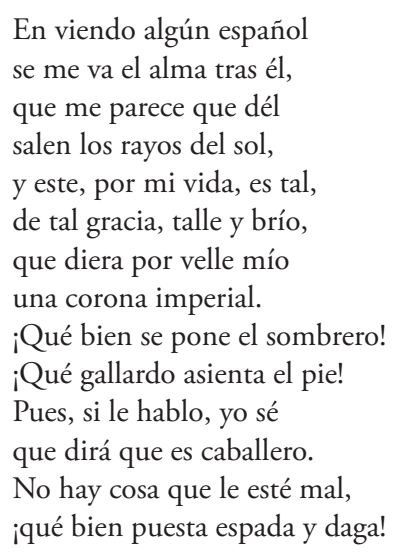

23. Gonzalo Céspedes y Meneses, Poema Trágico del español Gerardo, (Primera edición de Madrid, 1615) (cito por la edición de Madrid, 1686).

24. Vicente Espinel, Vida del escudero Marcos de Obregón, (primera edición de Madrid, de 1618) Madrid, Relación segunda, descanso XXI.

25. A. de Contreras, Discurso de mi vida; cito por la edición de Madrid, 2005. Cap. 6. 
Pues, ¿qué le diré que haga, que no vuele a un ave igual? Saben amar con regalos, y ya tan diestros están, que de cuando en cuando dan, con los regalos los palos. ¡Oh bizarría española! ${ }^{26}$.

Indudablemente, estos efectos tuvieron que ser de los que más provocaran el aplauso en la comedia española. Y, por ello, se repiten con cierta frecuencia. En el Acto II de esta misma obra, la dama Marcela se expresa en parecidos términos dirigiéndose a la flamenca Aynora:
Esos son los hombres, boba, que no esotros mariöles ${ }^{27}$; ese brío de españoles es lo que las almas roba. ¿Qué vitoria más honrada en los amorosos lazos que ver humilde en tus brazos la cara de un hombre arada? Y es más conforme a razón querer la mujer al hombre que tiene famoso nombre, y de valiente opinión; porque allá en la astrología ama Venus tiernamente al hombre cuyo ascendiente tiene a Marte, reina mía; y si de Ovidio sabe el arte, verá su amor tan liviano que no bastaba Vulcano para apartalle de Marte; y así los hombres marciales aman siempre las mujeres ${ }^{28}$.

Como si el español fuera un superhombre..., o mejor, un verdadero hombre, como, en el nivel supremo de arrogancia, llega a decir la dama Marcela al tudesco Bisanzón en esta misma obra:

\author{
BISANZÓN: ¿Quién es? \\ MARCELA: Un hombre. \\ BISANZÓN: Un hombre es sol. \\ MARCELA: Entiéndese un español, \\ ¿en el talle no lo ves? \\ BISANZÓN: ¿En diciendo hombre se entiende \\ un español?, ¿̇no son hombres
}

26. Lope de Vega, El asalto de Mastrique..., Acto I, p.13.

27. Maricones.

28. Lope de Vega, El asalto de Mastrique..., Acto II, p. 27. 


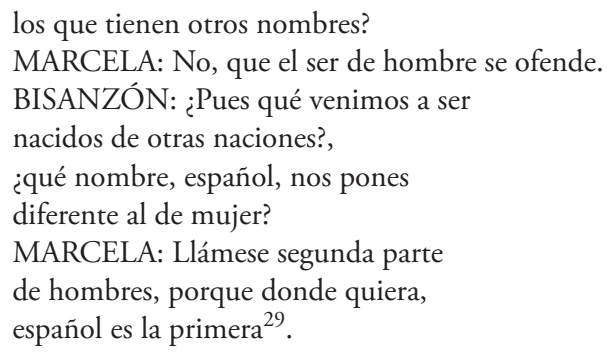

Como hemos señalado más arriba, apenas necesitan comentario tan expresivos versos que, sin duda, debían de hacer el deleite del público.

Por supuesto, la realidad no era exactamente esa (ya lo hubieran querido los soldados españoles de aquellos rudos tercios...), pero sí debía haber algo de esa atracción, especialmente en momentos determinados. No hay nada más que recordar la famosa anécdota de Don Juan de Austria cuando llegó a Mesina después de salir victorioso de Lepanto: la mitad de las damas de la ciudad querían yacer con el héroe del momento, cosa que también aprovechó el bastardo real para "compensarse " de los duros fragores del combate.

\section{Arrogancia española}

Algunos historiadores han manifestado, desde diferentes puntos de vista, que, por su comportamiento, los españoles del siglo de Oro se creían diferentes e incluso superiores que los miembros de las demás naciones; especialmente los castellanos. En este sentido, Rodríguez Salgado es una de las autoras que mejor presenta este hecho cuando afirma que en el proyecto común que guiaba los pasos de la Monarquía Hispánica, Castilla se fue convirtiendo cada vez más en el corazón de un Imperio que luchaba por Dios. La residencia del monarca allí suscitaba la idea, cada vez más compartida, de que los castellanos, y, también los españoles en general, eran especiales y diferentes, hasta el punto de tener que asumir unas responsabilidades particulares que les asignaba la Divinidad ${ }^{30}$. En este contexto, como subrayaba Felipe Ruiz Martín, los soldados españoles iban pavoneándose por los campos de batalla de Europa como lo que eran, unos conquistadores ${ }^{31}$.

Estos aires arrogantes no sólo no eran censurados por la población civil española, sino que eran vivamente aplaudidos, especialmente en determinados espacios de representación cultural, como en la poesía épica o en las veladas teatrales. Podemos ver, por ejemplo, síntomas de esa afección hacia «la española arrogancia», en los versos de La Dragontea, de Lope de Vega:

29. Ibidem., Acto III.

30. M.J. Rodríguez Salgado, «Patriotismo y política exterior en la España de Carlos V y Felipe II», en F. Ruiz Martín, La proyección europea de la Monarquia Hispánica, Madrid, 1996.

31. F. Ruiz Martín, La proyección europea de la Monarquia Hispánica, Madrid, 1996 (Introducción). 
Españoles hidalgos, envidiados por las armas de todas las naciones, temidos, perseguidos, y estimados por vuestros indomados corazones. Sangre de los católicos soldados, que han puesto los cristíferos pendones en las remotas playas de Occidente, peregrina ocasión tenéis presente ${ }^{32}$.

En el teatro, este tipo de mensajes eran recibidos por un público más amplio y con una procedencia social más diversa, aunque con la misma intensidad de colores para retratar esa imagen de superioridad del soldado español. Cuando, por ejemplo, en Los Guanches de Tenerife, el capitán Castillo se encuentra con la princesa guanche Dácil, a la que confunde con un ángel que no entendía bien las palabras del soldado castellano, el español, con un tono increíblemente presuntuoso, le contesta:

Poco te entiendo.

Hará poco que eres ángel, porque serlo más tiempo hablar español supieras ${ }^{33}$.

Aunque también se refleja con vívidos colores el orgullo infinito de los soldados españoles con sus propios compañeros de profesión o, incluso, sus superiores. En los bellísimos y famosos versos de Calderón de El sitio de Bredá podemos ver esta realidad:

Nunca la sombra vil vieron del miedo, y aunque soberbios son, son reportados. todo lo sufren en cualquier asalto, sólo no sufren que le hablen alto ${ }^{34}$.

Aunque también, en la enorme complejidad de la comedia barroca, se puede ver una autocrítica de la arrogancia en esta misma obra de El sitio de Breda. En este sentido, Calderón no puede ser más claro cuando una dama flamenca pregunta a Don Vicente Pimentel:

FLORA: ¿Sois español?

VICENTE: Sí. ¿¿En qué lo visteis?

FLORA: Lo vi

en que sois tan arrogante.

no queréis ignorar nada,

todo a su brío lo fía

la española bizarría,

con presunción confiada ${ }^{35}$.

32. Lope de Vega, La Dragontea, edición del Museo Naval, con estudio introductorio, de Gregorio Marañón, Madrid, 1935, Canto VIII, Núm. 513.

33. Lope de Vega, Los guanches de Tenerife, edición de Madrid, de 1961, Acto I, Cuadro III.

34. P. Calderón de la Barca, El sitio de Bredá...., Jornada I, Escena III, p. 110.

35. P. Calderón de la Barca, El sitio de Bredá...., Jornada II, Escena XV, p. 120. 


\section{CREACión de ESTADOS DE OPINIÓN}

Evidentemente, este tipo de mensajes muy del gusto del público que se lanzaban desde los autores en busca de una buena receptividad de sus obras, debía tener sus efectos en la creación de un determinado estado de opinión. Con determinados planteamientos como los que hemos visto podía incluso incentivar el grado de afición a las "cosas de la guerra» o, cuando menos, rebajar la imagen de los efectos negativos en la población civil de los costes humanos y económicos de los conflictos bélicos; especialmente, como era el caso de España, cuando la guerra solía estar en el exterior. Además, más allá de la propaganda más explícita y oficial, creaba más intensas fidelidades a la causa común cuando se demonizaba al adversario y se le presentaba como inhumano y cruel. La imagen del enemigo va cobrando así una determinada forma capaz de crear lealtades también desde este punto de vista; más indirecto, pero igualmente -o más- efectivo de este espacio cultural de la literatura de ficción.

Por ejemplo, una pluma como la de Cervantes debía tener por fuerza una importante carga de persuasión cuando calificaba, con los tonos más vivos, a los turcos como inhumanos. En la historia del cautivo, en el Quijote, pone en boca de este personaje las siguientes significativas palabras:

Y, aunque la hambre y desnudez pudiera fatigarnos a veces, y aun casi siempre, ninguna cosa nos fatigaba tanto como oír y ver, a cada paso, las jamás vistas ni oídas crueldades que mi amo usaba con los cristianos. Cada día ahorcaba el suyo, empalaba a éste, desorejaba aquél; y esto, por tan poca ocasión, y tan sin ella, que los turcos conocían que lo hacía no más de por hacerlo, y por ser natural condición suya ser homicida de todo el género humano ${ }^{36}$.

De una forma más específica, refiriéndose al terrible episodio de la toma de Famagusta, en Chipre, en la que los turcos mostraron todo tipo de crueldades en la antesala de la batalla de Lepanto, Ercilla transmitía en su famosísima Araucana las mencionadas atrocidades y la traición (faltando a la palabra dada para la rendición) que llevaron a cabo los otomanos. Concretamente, empleaba los siguientes versos:

\footnotetext{
Y sacando una armada poderosa, de todas sus provincias allegada, en la vecina Cipro, isla famosa, descargará la furia represada; y con espada cruda y rigurosa será la tierra dellos ocupada, entrando a Famagusta ya batida, sobre palabra falsa y fe mentida ${ }^{37}$.
}

36. M. de Cervantes Saavedra, El ingenioso hidalgo Don Quijote de la Mancha, (primera edición de la primera parte en 1605 y de la segunda en 1615), cito por la edición de J. Pérez del Hoyo, Madrid, 1963. I parte, p. 212.

37. En el Canto XVIII de la Araucana. 
Igualmente, siguiendo con la literatura épica, Fernando de Herrera, en su Relación de la guerra de Cipre..., ofrece una imagen de los turcos como moralmente execrables y con unos motivos tremendamente injustos para hacer la guerra ${ }^{38}$.

Imágenes como estas iban en la dirección -insistimos, no necesariamente intencionada y provocada directamente desde el poder- de crear un caldo de cultivo favorable al reclutamiento ante tamańas crueldades e injusticias que se estaban cometiendo contra el pueblo español. Y así, en la narrativa, por ejemplo, a veces se presenta el reclutamiento con unos tintes positivos que en nada tienen que ver con las penalidades que suponía en la grandísima mayoría de los casos. El personaje del padre de dońa Isabel, en los Desengaños amorosos de María de Zayas, se alista rápidamente en el ejército para pacificar Cataluña. Según un estudio actual sobre esta obra, María de Zayas estaba realmente preocupada por esta cuestión, y llegará a reprochar a los caballeros el no acudir con rapidez en ayuda del rey. La propia Doña Isabel llegará a decir en la obra:

Sucedió en este tiempo el levantamiento de Cataluña, para castigo de nuestros pecados, o sólo de los míos, que aunque han sido las pérdidas grandes, la mía es mayor: que los muertos en esta ocasión ganaron eterna fama, y yo, que quedé viva, ignominiosa infamia. Súpose en Murcia cómo Su Majestad (Dios le guarde) iba al ilustre y leal reino de Aragón, para hallarse presente en estas civiles guerras; y mi padre, con quien había gastado lo mejor de su mocedad en servicio de su rey, conoció lo que le importaban a Su Majestad los hombres de su valor; se determinó irle a servir, para que en tal ocasión le premiase los servicios pasado y presentes, como católico y agradecido rey...

Sigue diciendo el relato que ella y su madre quisieron ir con él, («..., como nińa, deseosa de ver tierras...»)

Habló mi padre a Su majestad, que, informado que había sido en la guerra tan gran soldado, y que aún no estaban amortiguados sus bríos y valor, y la buena cuenta que siempre había dado de lo que tenía a su cargo, le mandó asistiese al gobierno de un tercio de caballos, con título de maese de campo, honrando primero sus pechos con un hábito de Calatrava... ${ }^{39}$.

Este tipo de planteamientos podían condicionar también la capacidad para llevar a cabo una onerosa política internacional -como la que, de hecho, emprendió, en diferentes contextos, la Monarquía Hispánica- en cuanto a la

38. F. de Herrera, Relación de la guerra de Cipre, y suceso de la batalla naval de Lepanto, Sevilla, 1572.

39. María de Zayas, Desengaños amorosos, primera edición de Zaragoza 1647 (cito por la edición de Cátedra cuidada por Alicia Yllera, Madrid, 1983, p. 129). Por otra parte, esa falta de sintonía de los grandes caballeros con la política de alistamiento real también se manifestó, como se ha demostrado, en otros conflictos como el de Portugal. Vid. D. García Hernán, «La nobleza castellana y el servicio militar: permanencias y cambios en los siglos XVI y XVII a partir de los conflictos con Portugal», en E. García Hernán y D. Maffi (coords.), Guerra y sociedad en la monarquía hispánica: política, estrategia y cultura en la Europa Moderna (1500-1700), Madrid, 2006. 
imagen que se transmitía sobre ésta a la sociedad. Es más; se pudo llegar a ver determinadas posturas, como la posibilidad que algunos llegaran a plantear a Felipe II de la posible conquista, no ya de Jerusalén, sino de la mismísima China, que rayaban en la locura ${ }^{40}$.

Así, Bartolomé Leonardo de Argensola, en su obra poética Canción a la nave de la Iglesia con motivo de la victoria de Lepanto habla de la expansión hacia oriente de las fuerzas cristianas; esto es, de lo que los mandos militares llamaban «la empresa de Levante», de esta guisa:

\footnotetext{
Veránse entonces las paredes llenas de despojos opimos por tu gente, oh vencedora nave, arrebatados. Mas ¿qué venganza general ordenas? ¿Qué multitud te sigue hacia el oriente insigne de católicos soldados, a vencer obligados, o morir por vengar el postrer godo? Mas, ¿qué flotas, qué ejércitos son éstos, en media luna opuestos? Agora es tiempo de acabar del todo, oh fieles argonautas, pues seguros podéis llegar hasta los santos muros ${ }^{41}$.
}

De esta forma, como se puede desprender de la lectura de las líneas que anteceden, estamos convencidos de que la literatura de ficción, no necesariamente propagandística en su naturaleza, ha jugado también un papel relevante en la historia militar de España. No tanto (que también) como objeto histórico (la literatura como representación cultural derivada de los acontecimientos reales), sino también como sujeto histórico. Es decir, los estados de opinión que creaba al mismo tiempo eran condicionantes que se podían tener en cuenta para llevar a cabo una u otra acción militar; o, por lo menos, podían contribuir a crear una determinada imagen de la realidad en el fundamental desarrollo de la actitud de Espańa ante la política internacional y el mundo de la guerra.

Además, había momentos en que los propios escritores se sentían identificados con esta misión. Herrera utiliza su Relación de la guerra de Cipre... para refutar los ataques lanzados contra España por parte de los italianos y, a la vez, para que la imagen de Espańa ante el extranjero vaya de la mano con los hechos sobresalientes de los españoles, dado que hasta ese momento, según el poeta sevillano, los escritores españoles no habían sabido dar a conocer bien las «excelencias» de esos hechos.

40. G. Parker, El éxito nunca es definitivo, Madrid, 2001.

41. Bartolomé Leonardo de Argensola, Canción a la nave de la Iglesia con motivo de la victoria de Lepanto, en L. Rosales, L. F. Vivanco (antología y prólogos), Poesía heroica del imperio, Madrid, 1940-43, pp. 535-539. 
Y así, no es casualidad que sea a partir del siglo XVI cuando se cree el estereotipo o caracterización de lo español y de los españoles. En el terreno de los hechos y de la historia, sabemos que en buena medida esto se dio porque, en la tendencia a la cohesión (al menos en este terreno político-militar), se va a crear un caldo de cultivo que pudo evitar un estado de rebelión más o menos constante, y promocionar, en su lugar, guerras de grandes dimensiones contra potencias extranjeras. La ideología común a partir de los planteamientos políticos y morales, ligados con las tradiciones constantes, se va viendo cada vez más clara. Se va creando, pues, un sentimiento de lealtad a la patria y a la dinastía, que, en aquella época eran los cimientos de cada estado. Es esto, precisamente, lo que permitió a los monarcas hispanos apuntalar su hegemonía dando al mismo tiempo una imagen imborrable de la potencia de España ${ }^{42}$. Creemos sinceramente que, en este desarrollo de un proyecto común, la identificación de la población ante los problemas militares a través de la literatura pudo jugar un papel importante, aunque imposible de determinar con exactitud en qué medida.

Thompson llamaba la atención hace unos años sobre la ideología de ese proyecto común que sustenta buena parte del esfuerzo militar hispano, y la importancia que tiene en ello el concepto de Monarquía de España:

[...] aunque no podamos decir cómo sucedió ni quien fue su promotor, ni si respondió a un plan elaborado, tal vez la contribución más importante a la defensa de «los reinos y estados» del rey de España fue el surgimiento, en torno a 1600, de un nuevo vocablo que expresó o al menos facilitó la existencia de una conciencia común de pertenencia a una nueva entidad política compuesta. Lo que iba a conocerse como la «Monarquía de España» apenas si tenía existencia como concepto lingüístico o político antes de la década de 1590; durante los primeros años del siglo XVII empezó a tener un uso corriente cada vez mayor en la terminología del discurso político habitual; y hacia la década de 1620 iba a ser tanto justificación ideológica como matriz organizativa para una reciprocidad de contribuciones a la defensa común de lo que podía representarse como una unidad singular y orgánica ${ }^{43}$.

Pues bien, después de lo expuesto en estas páginas que ahora cerramos, pensamos que podemos estar algo más cerca de poder responder en parte a los interrogantes de Thompson sobre esa conciencia común en cuanto a "cómo sucedió», «quién fue su promotor», o «si respondió a un plan elaborado»....

42. M. J. Rodriguez Salgado, «Patriotismo y política exterior...»

43. I. A .A. Thompson, «La guerra y el soldado», en A. Feros y J. Gelabert, España en tiempos del Quijote, Madrid, 2004. 